\title{
38. COMMISSION POUR L'ECHANGE DES ASTRONOMES
}

\section{Report of Meeting, 26 August 1964}

President: M. Minnaert.

SECRETARY: F. B. Wood.

The President announced that in the future this group will be a Committee of the Executive Committee instead of a Commission, but that this will involve no change in its status and power.

The Draft Report was approved with minor additions and alterations. Rochester, Osten, and Nashville are to be added to the list of facilities for visiting astronomers; other observatories are yet to be heard from. Dr P. M. Routley announced that the American Astronomical Society now awards eight Foreign Visiting Professorships annually instead of the four previously announced.

The financial report showed a sharp increase in awards for travel funds for exchange of

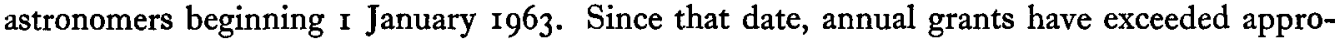
priations, but because of smaller expenditures before that date, an unexpended balance still remains. It was voted to request the Financial Committee to continue appropriations of $75^{\circ 0}$ dollars annually for the next three years.

The President reported briefly on some of the work of UNESCO and ICSU in working for improved facilities for visitors in educational institutions. Consideration is being given by the IAU to a new Commission on the Teaching of Astronomy, but it is suggested that its function be kept apart from that of Commission 38 .

The President reported on types of cases in which as a matter of policy grants had been refused in the past; this economy in the use of the available means was approved. The Commission recommended that the President be permitted to pay travel expenses for married couples in cases where the visits equalled or exceeded six months duration, and that, at the discretion of the President and Vice-President, limited grants could be made for the travel of very young children. It was decided that in the future those who have received a grant should always report to the President about the scientific results of their stay abroad.

A general discussion was held on the idea of a special diploma to be given foreign students, unable to meet the requirements for regular degrees at the host university. This idea was not approved by the Commission. It was considered that the possibility be explored of recognition of the bachelor's diploma or equivalent of foreign institutions as sufficient for admission to graduate study by those institutions which do not now do so. Dr Sahade pointed out that in Argentina, nationals of other countries receive free tuition and suggested this as a possible means of training more astronomers for other Latin-American countries.

The exchange of students already at the graduate level was discussed and the President was empowered to appoint a Committee to consider this. The President appointed M. V. Migeotte, Chairman, P. M. Routley, H. G. Kienle, and one other member to be suggested by Migeotte.

The appointment was announced of Migeotte as Vice-President of the Commission in place of Swings. Wood (F. B.) served as secretary for the current session. Bowen, Mikhailov, Woolley were at their request removed from the Organizing Committee and Babcock, Brück, Martynov were recommended for their places to the Executive Committee of the Union. 